\title{
Robert Murrell Stevenson (1916-2012)
}

Con profundo pesar, a nombre de la Revista Musical Chilena, comunicamos el sensible fallecimiento del Prof. Dr. Robert Murrell Stevenson (Q.E.P.D.). Nació en Melrose, Nuevo México, en los Estados Unidos el 3 de julio de 1916. Falleció en la ciudad de Los Angeles, California, el 22 de diciembre de 2012.

Dentro de su variado quehacer fue historiador del pasado musical americano. Como investigador comprendió que el historiador musical no puede enfocar la música latinoamericana de la misma manera que los musicólogos historiadores discuten la música europea. Debido a la interacción tan compleja entre las diversas tradiciones musicales, los musicólogos deben forzosamente tener un enfoque amplio de la actividad musical latinoamericana si realmente desean asir su sentido profundo y verdadero significado.

Esto fue precisamente lo que hizo con magistral jerarquía durante casi setenta años de actividad como estudioso, tanto en sus libros, monografías, separatas, artículos como en sus reseñas y notas a discos y programas. El Profesor Stevenson desenterró una cantidad impresionante de nuevas informaciones sobre música sagrada y profana española junto a la teoría musical de los siglos XV y XVI, la que complementó con trabajos igualmente fundamentales sobre la música sagrada de las Américas, en lugares como México, Guatemala, Puerto Rico, Venezuela, Ecuador, Colombia, Perú y Chile, entre otros. De similar importancia fueron sus descubrimientos en el campo de la música secular e instrumental durante el período colonial de las Américas. Sus trabajos sobre la ópera española y la música para el teatro peninsular durante el siglo XVII se equipararon de manera sustantiva con sus estudios sobre los comienzos de la ópera en el Nuevo Mundo. De manera similar, las publicaciones de sus investigaciones sobre la música sagrada y secular y la teoría musical en Portugal se complementaron con los resultados impresionantes de sus investigaciones y publicaciones sobre la música del Brasil. Otros vínculos entre el Nuevo Mundo y Europa quedaron fundamentados en sus trabajos sobre la influencia de Joseph Haydn, Fryderyk Chopin y Richard Wagner en América Latina.

Junto a la música de ancestro europeo, el Dr. Robert Stevenson aportó hitos musicológicos sobresalientes sobre la música amerindia y precolombina, con trabajos en profundidad sobre la historia de la música e instrumentos antiguos de los territorios Azteca e Inca. Las tradiciones africanas en las Américas fueron más que ampliamente abarcadas en su monografía sobre el legado afroamericano hasta 1800 .

Además de las tradiciones principales que plasmaron la música latinoamericana, su inteligencia inquisitiva lo impulsó hacia la historia de la música en los siglos XIX y XX de Latinoamérica, enfocada desde el punto de vista no solo de la música docta, sino que de la de tradición oral, las expresiones populares urbanas y otros géneros que habitualmente no se consideran dentro del marco musicológico habitual, como es el caso, por ejemplo, de los himnos nacionales. Este amplio enfoque también es evidente en el análisis que efectuara de la contribución de maestros afroamericanos y de los pueblos originarios a la música aculturada de las Américas.

Dentro de una perspectiva más amplia, la investigación del Profesor Robert Stevenson delimitó la contribución de Latinoamérica a la música europea. Un ejemplo es su descubrimiento de la descendencia americana de una danza tan característica del período barroco como fue la zarabanda. En este sentido, son igualmente importantes sus trabajos sobre el intercambio entre Latinoamérica y los Estados Unidos, su enfoque del tratamiento de la música de Latinoamérica, España y Portugal en enciclopedias internacionales de música y la ubicación de importantes fuentes europeas en Latinoamérica, 
como por ejemplo el manuscrito de Johannes de Garlandia que se conserva en la Biblioteca Nacional de Río de Janeiro.

El enfoque del Dr. Robert Stevenson de la historia de la música junto a las técnicas de investigación de las que hizo uso fueron tan originales como significativas. Abarcó todo el continuo de la actividad musical desde el punto de vista diacrónico, relacionándolo con el contexto cultural, económico y social. Para poder realizarlo se familiarizó en profundidad con todas las fuentes posibles, impresas o en manuscrito, musicológicas o no, que pudieran ser pertinentes directa o indirectamente al tema que investigaba. A pesar que la documentación de sus libros, monografías y artículos es realmente abrumadora, su brillante manejo de la lengua inglesa siempre ha producido un placer incomparable de la lectura. Su cuidadosa búsqueda en las colecciones o en los antecedentes sobre música y músicos que se preservan en los archivos y bibliotecas de América del Norte, Central y Sur, además de las del Caribe, revelaron al mundo musicológico muchas de las riquezas que yacían en el Nuevo Mundo olvidadas durante siglos. Su análisis de las obras musicales abarcó no solo la música misma, sino que también su significado musical en relación con su uso y función, además de su conexión con la literatura, la religión y con otros aspectos.

Junto a sus trabajos musicológicos, el Profesor Stevenson editó mucha música secular y religiosa de las Américas y de la Península Ibérica para el uso de investigadores e intérpretes. Las grabaciones de música de Latinoamérica impulsadas por el profesor Stevenson permitieron al auditor medio gozarla tanto en las Américas como en Europa. Contribuyó a que la música latinoamericana e ibérica llegara a las más prestigiadas revistas y enciclopedias del mundo musicológico, estableciendo de esta manera mejores canales de comunicación entre Latinoamérica y el resto del mundo y entre los países latinoamericanos mismos. Contribuyó además a que la música de Latinoamérica afianzara su lugar dentro del gran contexto de las músicas del mundo. Su integridad como investigador junto a sus profundos conocimientos de las más importantes disciplinas humanísticas y su suprema capacidad para correlacionar estas disciplinas con la historia de la música, solo es comparable con la de sabios del nivel de los grandes humanistas de Latinoamérica del siglo XIX, como don Andrés Bello.

En lo que respecta al estudio de la cultura musical americana el trabajo del Dr. Stevenson se vinculó con la labor que grandes y dedicados pioneros realizaron en los diferentes países americanos. Entre ellos está aquel insuperable americanista que fuera Francisco Curt Lange. Junto a él se puede mencionar, sin ánimo de exhaustividad, a Guillermo Furlong-Cardiff, Pedro Grenón, José Torre Revello y Vicente Gesualdo en Argentina; Rodolfo Barbacci en Argentina y Perú; Julia Elena Fortún en Bolivia; Luis Heitor Corrêa de Azevedo en Brasil; Eugenio Pereira Salas en Chile; Andrés Martínez Montoya y José Ignacio Perdomo Escobar en Colombia; Alejo Carpentier y Pablo Hernández Balaguer en Cuba; Miguel Bernal Jiménez, Jesús Estrada, Gabriel Saldívar y Jesús Bal y Gay en México; Carlos Leonhardt sobre la música misional en lo que hoy es Paraguay; Rodolfo Holzmann, César Arróspide de la Flor, Guillermo Lohmann Villena, Andrés Sas, Rubén Vargas Ugarte y Carlos Raygada en Perú; Juan Bautista Plaza y José Antonio Calcaño en Venezuela, además de Lauro Ayestarán en Uruguay.

Impulsó el Dr. Stevenson con denuedo y desinterés a los musicólogos latinoamericanos a la investigación de archivos ubicados fuera de sus países de origen. Baste recordar el caso de nuestro recordado musicólogo Samuel Claro Valdés. Él realizó una gira americana de estudios archivísticos con el mismo Dr. Stevenson en 1966, después de la estadía de este último como profesor invitado de la Universidad de Chile, en el marco del programa de intercambio entre esta universidad y la Universidad de California, financiado por la Fundación Ford. Fruto de este viaje, entre otros trabajos, es la monumental Antología de la música colonial de América del Sur del profesor Claro, la primera de su género en el continente americano y que ha tenido una fructífera proyección hasta nuestros días. Este impulso denodado y desinteresado se proyectó además en otros ámbitos. Después de obtener en 1985 el Premio Interamericano de Cultura "Gabriela Mistral" discernido por la Organización de los Estados Americanos, el profesor Stevenson donó ese mismo año el importe del premio (quince mil dólares norteamericanos) al Inter-American Music Friends y al Consejo Interamericano de la Música (CIDEM), para establecer el premio bienal "Robert Stevenson" en Historia de la Música y Musicología Latinoamericana. Desde entonces este premio ha servido para reconocer la labor de muchos y valiosos musicólogos americanos.

Igualmente generosa y brillante fue su labor como profesor en la Universidad de California, Los Angeles (UCLA). Tengo el honor de haber sido el primer candidato doctoral que lo tuviera como su profesor guía, con mi disertación sobre las misas de Francisco Guerrero (1528-1599), completada en 1972. Posteriormente otros colegas de los Estados Unidos, América y España tendrían un privilegio 
similar. Constituyó en mi caso una experiencia única el poder conocer de cerca la prodigiosa sabiduría decantada de un gran maestro, la que mostraba con generosidad y brillantez en su labor como docente tanto de pregrado como de postgrado Sus clases tenían como eje un discurso variadamente matizado sobre música, sociedad y cultura que el Dr. Stevenson impartía sin ningún apoyo escrito. Fue durante esta época que me fue posible apreciar además otras de sus múltiples facetas, la de un brillante pianista y la de un destacado compositor.

Fue un colaborador asiduo de la Revista Musical Chilena, publicación a la que le brindó además un apoyo permanente e inquebrantable. Escribió numerosos artículos sobre sus múltiples especialidades como investigador, además de necrologías y reseñas de publicaciones. Se puede señalar como una muestra el $N^{\circ} 81-82$ correspondiente a julio-diciembre de 1962. Es el primer número de la Revista dedicado en su integridad a la música colonial americana y que contó con la participación de investigadores ilustres como Andrés Sas, Carlos Vega, Lauro Ayestarán, Vicente Gesualdo, Luis Heitor Correa de Azevedo, José Antonio Calcaño, Pablo Hernández Balaguer y el Dr. Stevenson. Gracias a este logro, y a otros ulteriores, la Revista Musical Chilena se constituyó durante la década de los años 60 como uno de los referentes obligados sobre esta temática en idioma castellano.

Estas y otras facetas del valioso legado del Dr. Robert Stevenson se han proyectado hoy en la labor que musicólogos de América Latina y del resto del mundo realizan acerca del legado colonial y decimonónico americano. El potente intelecto del Dr. Stevenson señaló un camino en cuanto a la necesidad que el trabajo histórico considere el estudio de las fuentes que arrojen luz tanto acerca de la música como de su contexto sociocultural. De ahí las interacciones entre la historia de la música con la historia general y con tantas otras disciplinas de las ciencias humanas y de las ciencias sociales que se han desarrollado en los últimos años, las que permiten a los musicólogos el poder adentrarse a cabalidad en el proceso de conocer el valor patrimonial de nuestro pasado americano.

Prof. Dr. Luis Merino Montero

Director

Revista Musical Chilena

lmerino@u.uchile.cl 